\title{
The effect of span length and girder type on bridge costs
}

\author{
Mustafa Batikha ${ }^{1, *}$, Osamah $\mathrm{Al} \mathrm{Ani}{ }^{1}$, and Taha Elhag ${ }^{1}$ \\ ${ }^{1}$ School of Energy, Geoscience, Infrastructure and Society; Heriot-Watt University, Dubai, U.A.E
}

\begin{abstract}
Bridges have an important role in impacting the civilization, growth and economy of cities from ancient time until these days due to their function in reducing transportation cost and time. Therefore, development of bridges has been a knowledge domain in civil engineering studies in terms of their types and construction materials to confirm a reliable, safe, economic design and construction. Girder-bridge of concrete deck and I-beam girder has been used widely for short and medium span bridges because of ease and low-cost of fabrication. However, many theoretical and practical investigations are still undertaken regarding the type of beam girder; i.e steel composite or prestressed concrete. This paper evaluates the effect of bridge span and the type of girder on the capital cost and life cycle costs of bridges. Three types of girders were investigated in this research: steel composite, pre-tensioned pre-stressed concrete and post-tensioned pre-stressed concrete. The structural design was analyzed for 5 span lengths: 20, 25, 30, 35 and $40 \mathrm{~m}$. Then, the capital construction cost was accounted for 15 bridges according to each span and construction materials. Moreover, the maintenance required for 50 years of bridge life was evaluated and built up as whole life costs for each bridge. As a result of this study, the influence of both span length and type of girder on initial construction cost and maintenance whole life costs were assessed to support the decision makers and designers in the selection process for the optimum solution of girder bridges.
\end{abstract}

\section{Introduction}

Bridges have an important role in impacting the civilization life due to their function in reducing transportation cost and time. Therefore, the demand of bridges has been expanded dramatically these days in most countries. For example, it is registered that almost 1500 bridges per year were built in the USA between years 1996 to 2006 [1]. In Dubai, it is recorded that bridges reaches a number of 347 at the end of 2012[2]. Subsequent to this considerable increase in bridges number, low cost bridge construction is a big challenge facing the designer.

In this study, the cost of simply supported I-beam girder-bridge is investigated since it is the most popular because of ease and low-cost of fabrication together with its suitability for short and medium span. Furthermore, Boatman (2010)[3] explores that the service life for

\footnotetext{
* Corresponding author: m.batikha@hw.ac.uk
} 
steel composite I-Beam or pre-stressed I-beam is about 45 years which is 17 years more than using box-girder beam. This is another reason behind choosing I-beam for this study. On the other hand, three kinds of construction materials are selected for the girders of bridge: steel composite girder, pre-tensioned pre-stressed concrete girder and posttensioned pre-stressed concrete girder. Then, the effect of bridge span and the type of girder on the capital cost and life cycle costs of bridges is evaluated.

Many researchers have tried to answer the question of girder-bridge cost in respect of both span length and life cycle. For example, Jagtab and Shahezad (2016) [4] studied various spans of I-girder bridge to compare between the initial cost of using pre-stressed concrete girder or steel girder. In their work, it was found that steel beam is preferable for short span length up to $15 \mathrm{~m}$. Whereas, pre-stressed concrete girder is more economical in $37 \%$ for $24 \mathrm{~m}$ span length. The saving may reach $46 \%$ for $36 \mathrm{~m}$ span length. In 2016 , Singh etal.[5] discussed two different span lengths for I-beam girder bridge: $20 \mathrm{~m}$ and $25 \mathrm{~m}$. Life service of 100 years was taken into consideration in the cost estimation. As a conclusion of their work, the pre-stressed I-girder bridge is the lowest cost compared to the composite steel I-girder. The concluded saving was $10 \%$ and $15 \%$ for $20 \mathrm{~m}$-span and $25 \mathrm{~m}$-span respectively. It is worth mentioning that Florida Department Of Transportation (FDOT) estimates the average cost of construction Pre-stress concrete I-girder simple span bridge as $12 \%$ less than using steel girder [6]. However, more studies still need to be undertaken to answer the bridge cost question according to span and materials in use where this paper analysed these costs for different spans.

\section{Structural analysis of different simple-span bridges}

\subsection{Geometry, material properties and loading}

Five simply supported Bridges of different span-lengths were studied in this paper: 20, 25, 30,35 and $40 \mathrm{~m}$. The section of girder-bridge is shown in Figure 1. The distance among girders is $2.25 \mathrm{~m}$ with slab thickness of $200 \mathrm{~mm}$ and carriageway of $6.95 \mathrm{~m}$. The concrete barrier has a self-weight of $6.22 \mathrm{kN} / \mathrm{m}$. While, $5 \mathrm{kN} / \mathrm{m} 2$ was assumed for both asphalt selfweight and service loading. Using BD 37/01 (2002) [7], live loads was applied to bridge as HA-UDL of $12.4 \mathrm{kN} / \mathrm{m} 2$ plus HA-KEL of $32.9 \mathrm{kN} / \mathrm{m}$ and HB-45 unit as described in Figure 2. In this study, The total length of the HB vehicle was taken as $9.6 \mathrm{~m}$ which leads to most sever affect to the bridge.

The concrete material was considered to have a cylindrical characteristic compressive strength equals to $40 \mathrm{MPa}$ and modulus of elasticity of $35 \mathrm{GPa}$. While, the steel reinforcement has $460 \mathrm{MPa}$ yield strength and $200 \mathrm{GPa}$ elastic modulus. For pre-stressed section design, super low relaxation 7-wire strands were used. Each strand has $12.9 \mathrm{~mm}$ diameter and $186 \mathrm{kN}$ ultimate load. 


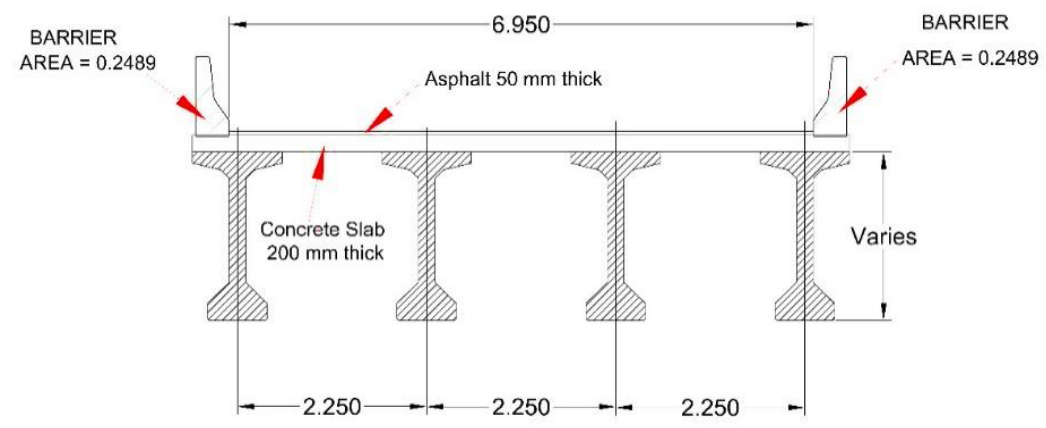

Fig. 1. Bridge cross section of 4 girder-system

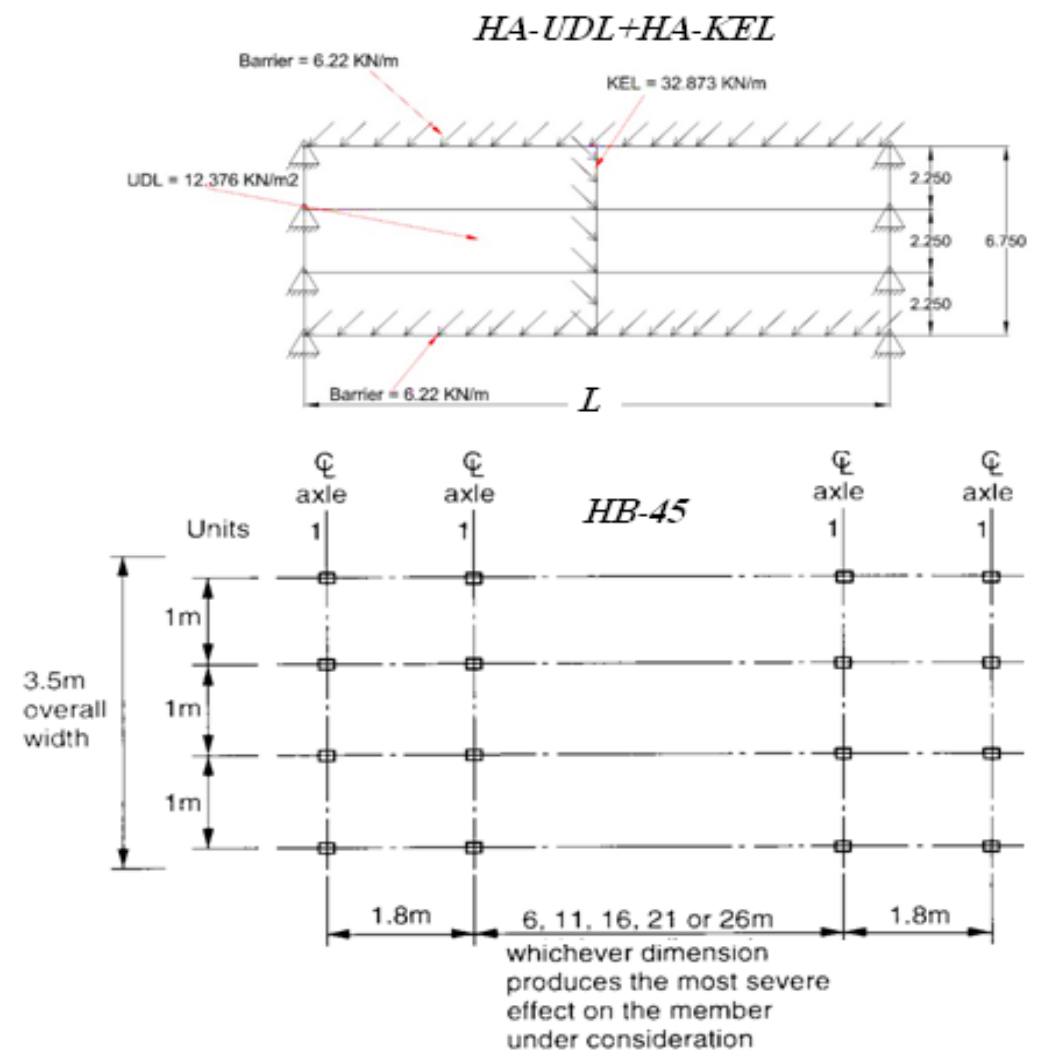

Fig. 2. Traffic live load applied to the bridge[7].

\subsection{FE modeling and results}

Using SAP2000-Ver 15.0.1[8], elastic analysis was performed for all bridges using estimated sections (Appendix A). Table 1 presents the dimensions properties, the ultimate internal forces produced by the current analysis and the capacity (resistance) of each section. Both shear resistance and bending resistance for each section were obtained using BS 5950-3.1:1990 [9] for composite section and BS 8110-1:1997 [10] for pre-stressed 
concrete section. From Table 1, it can be seen clearly that the section estimation was proper since the ultimate bending moment is almost same as bending capacity.

Figure 3 describes the relationship between the span length and depth of the girder for the three cases used in this research: composite section, pre-tensioned pre-stressed concrete and post-tensioned pre-stressed concrete. It can be explored that steel composite girder offers always lower depth up to $41 \%$ less for $40 \mathrm{~m}$ bridge span.

Table 1. Dimensions properties, ultimate internal forces and capacity for each section.

\begin{tabular}{|c|c|c|c|c|c|c|c|c|c|c|c|c|c|c|c|}
\hline \multicolumn{16}{|c|}{ Section Details and Properties of Girders } \\
\hline \multirow{2}{*}{$\begin{array}{l}\mathrm{Sr} \\
\text { No. }\end{array}$} & \multirow{2}{*}{$\begin{array}{c}\text { Girder } \\
\text { Length } \\
(\mathrm{m})\end{array}$} & \multirow{2}{*}{ Girder Type } & \multirow{2}{*}{$\begin{array}{c}\text { Girder } \\
\text { Depth } \\
\text { (m) }\end{array}$} & \multirow{2}{*}{$\begin{array}{c}\text { Girder \& } \\
\text { Salb Depth } \\
(\mathrm{m})\end{array}$} & \multirow{2}{*}{$\begin{array}{c}\text { Section } \\
\text { Area with } \\
\text { Slab }(m)^{2}\end{array}$} & \multirow{2}{*}{$\begin{array}{c}\text { Section Area } \\
\text { without Slab } \\
(\mathrm{m})^{2}\end{array}$} & \multirow{2}{*}{$\begin{array}{c}\text { Moment of } \\
\text { Inertia } \\
(\mathrm{mm})^{4} \cdot(10)^{1} \\
2\end{array}$} & \multicolumn{3}{|c|}{ No. of Tendons } & \multirow{2}{*}{$\begin{array}{c}\text { Force } \\
\text { in } \\
\text { Tendo } \\
\text { ns (KN) }\end{array}$} & \multirow{2}{*}{$\begin{array}{c}\text { Moment } \\
\text { Resis. } \\
(\text { KN.m) }\end{array}$} & \multirow{2}{*}{$\begin{array}{c}\text { ULS } \\
\text { Moment } \\
\text { (KN.M) }\end{array}$} & \multirow{2}{*}{$\begin{array}{l}\text { Shear } \\
\text { Resis } \\
.(\mathrm{KN})\end{array}$} & \multirow{2}{*}{$\begin{array}{c}\text { ULS } \\
\text { Shear } \\
\text { (KN) }\end{array}$} \\
\hline & & & & & & & & Bototm & Top & Total & & & & & \\
\hline & & & & & & & & & & & & & & & \\
\hline 3 & $40 \mathrm{~m}$ & Composite & 1.1 & 1.3 & & 0.0701 & & & & & & 13607 & 12228 & 7514 & 1361 \\
\hline 4 & $35 \mathrm{~m}$ & Pre-Tension & 1.8 & 2 & 1.055 & 0.605 & 0.5635 & $58 \mathrm{~B}$ & $4 \mathrm{~T}$ & 62 & 8073 & 12956 & 12602 & 812 & 1793 \\
\hline 5 & $35 \mathrm{~m}$ & Post-Tensiom & 1.8 & 2 & 1.035 & 0.585 & 0.3981 & $74 \mathrm{~B}$ & & 74 & 9635 & 12977 & 12336 & 1585 & 1793 \\
\hline 6 & $35 \mathrm{~m}$ & Composite & 0.92 & 1.12 & & 0.0494 & & & & & & 9552 & 9340 & 4080 & 1246 \\
\hline 10 & $25 \mathrm{~m}$ & Pre-Tension & 1.4 & 1.6 & 0.925 & 0.475 & 0.2967 & $43 \mathrm{~B}$ & $3 \mathrm{~T}$ & 46 & 5999 & 7663 & 7055 & 594 & 1466 \\
\hline 11 & $25 \mathrm{~m}$ & Post-Tensiom & 1.4 & 1.6 & 0.915 & 0.4648 & 0.2108 & $46 \mathrm{~B}$ & & 46 & 7163 & 7465 & 6879 & 1183 & 1466 \\
\hline 12 & $25 \mathrm{~m}$ & Composite & 0.91 & 1.11 & & 0.0286 & & & & & & 5390 & 5230 & 3083 & 1100 \\
\hline & 7 & & & & & f & & 0 & $3 \mathrm{~T}$ & 33 & & & & 101 & 2 \\
\hline 13 & $20 \mathrm{~m}$ & Pre-1 & 1.2 & 1.4 & 0.91 & .46 & 187 & $30 \mathrm{~B}$ & 311 & 33 & 4219 & 195 & $2 / 6$ & 481 & 1323 \\
\hline 14 & $20 \mathrm{~m}$ & Post-Tensiom & 1.2 & 1.4 & 5 & 0.4047 & 0.1435 & $31 \mathrm{~B}$ & & 1 & 4036 & 4686 & 4567 & 859 & 1323 \\
\hline 15 & $20 \mathrm{~m}$ & Composite & 0.835 & 1.035 & & 0.0224 & & & & & & 4108 & 3584 & 2490 & 1036 \\
\hline
\end{tabular}

\section{Cost analysis of different simple-span bridges}

This study carried out and compared two types of cost analysis for each bridge span: (a) comparison analysis for only the initial capital costs; and (b) cost analysis including the initial costs and 50-year life cycle costs encompassing the maintenance costs. The life cycle costs are derived using Eqs. (1)-(2) [11]:

$$
\begin{gathered}
F_{V}=P_{V}(1+i)^{n} \\
P_{V}=F_{V}[1 /(1+r)]^{n}
\end{gathered}
$$

where,

$F_{V}$ is Future Value of $n$ number of years.

$P_{V}$ is Present Value.

$i$ is the inflation rate.

$r$ is the interest rate. 


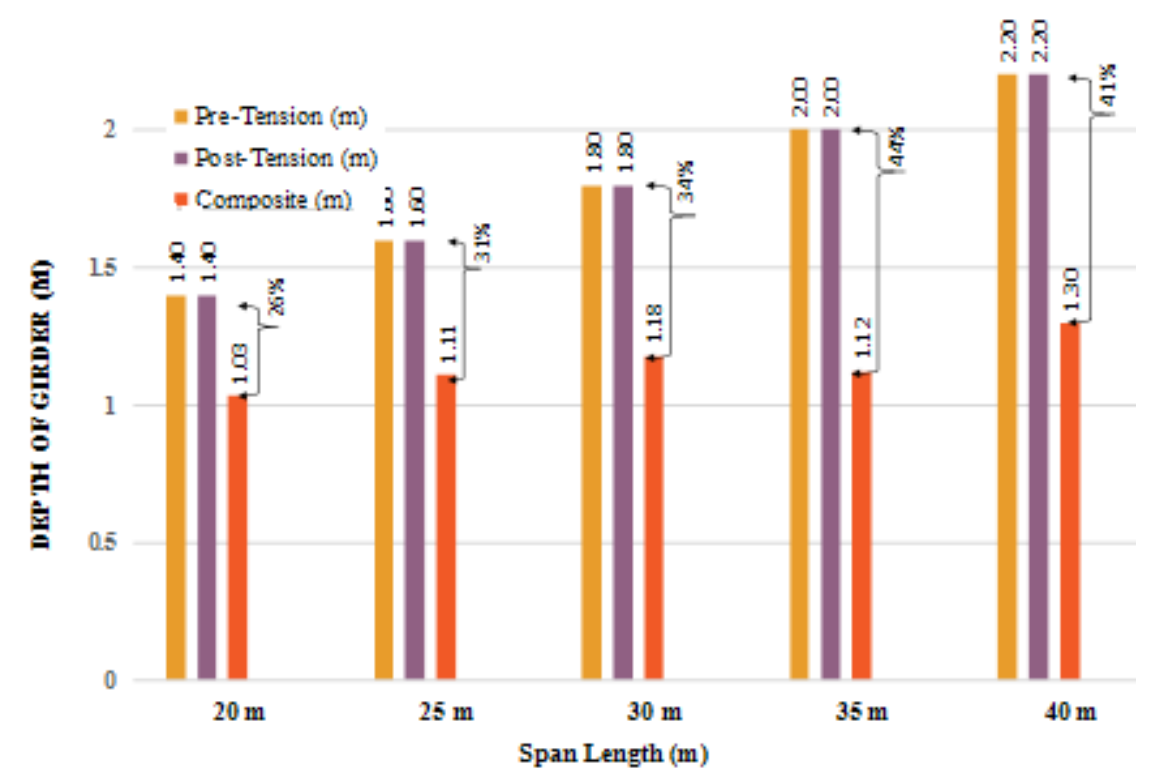

Fig. 3. The relationship between span and depth of the girder.

Following the preparation of the strutrual design for the three types of bridges with five lengths for each type, the material quantities have been calculated for each girder and listed in bill of quantities. These materials include: concrete, steel, strands, grounting, etc. In addition, the rate for each item in the BoQ has been based on average rates of previous projects in United Arab Emirates. The results of the analysis have been illustrated by the following bar-chart figures.

Figure 4 shows the total capital costs in Emirati Dirhams (DHS) of 4-girder bridges of different span and different section type. It is evident that for spans between $20 \mathrm{~m}$ and $30 \mathrm{~m}$, the composite girder has the least capital cost compared with the pre-tensined and post-tensioned girders. However, for spans between $35 \mathrm{~m}$ and $40 \mathrm{~m}$ the composite girder is much expensive. The reason for that might be because of the structural loads and depths of girders required for short, medium and long spans.

Whereas, Figure 5 exhibits the 50-year life cycle costs for same bridges. It is worth mentioning that the daily cleaning, which is required for all types of bridges, was not included in the maintenance analysis, because it will not make any difference for the comparison analysis of this study. The daily cleaning will only add the same constant cost for all types of girders. From Figure 5, it is clear that, except for the $20 \mathrm{~m}$ span, all other spans are more expensive with a composite girder compared to pre-tensined and post-tensioned girders. For both cases in Figures 4 and 5, the growth percentage in cost is increased as the span length is increased. 


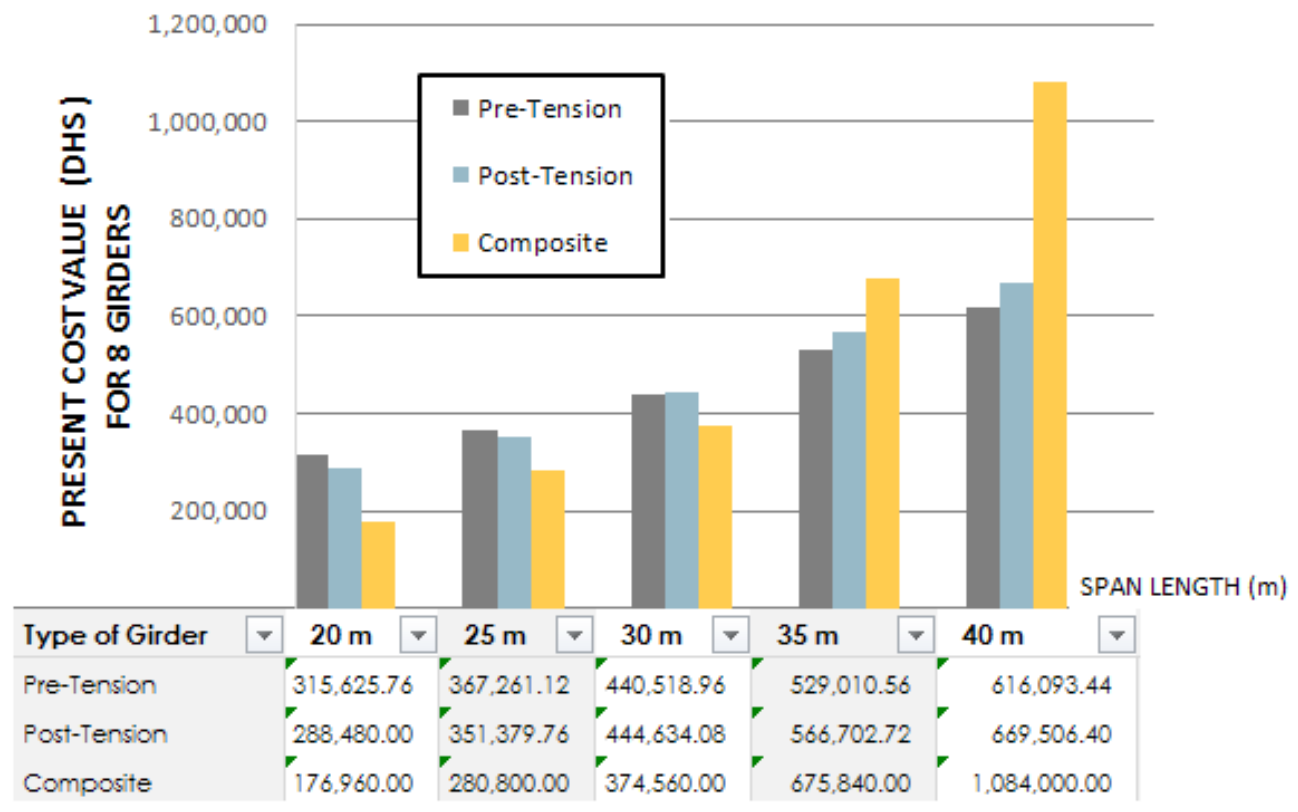

Fig. 4. The total capital costs (present value) for 8 girders of different span and section type.

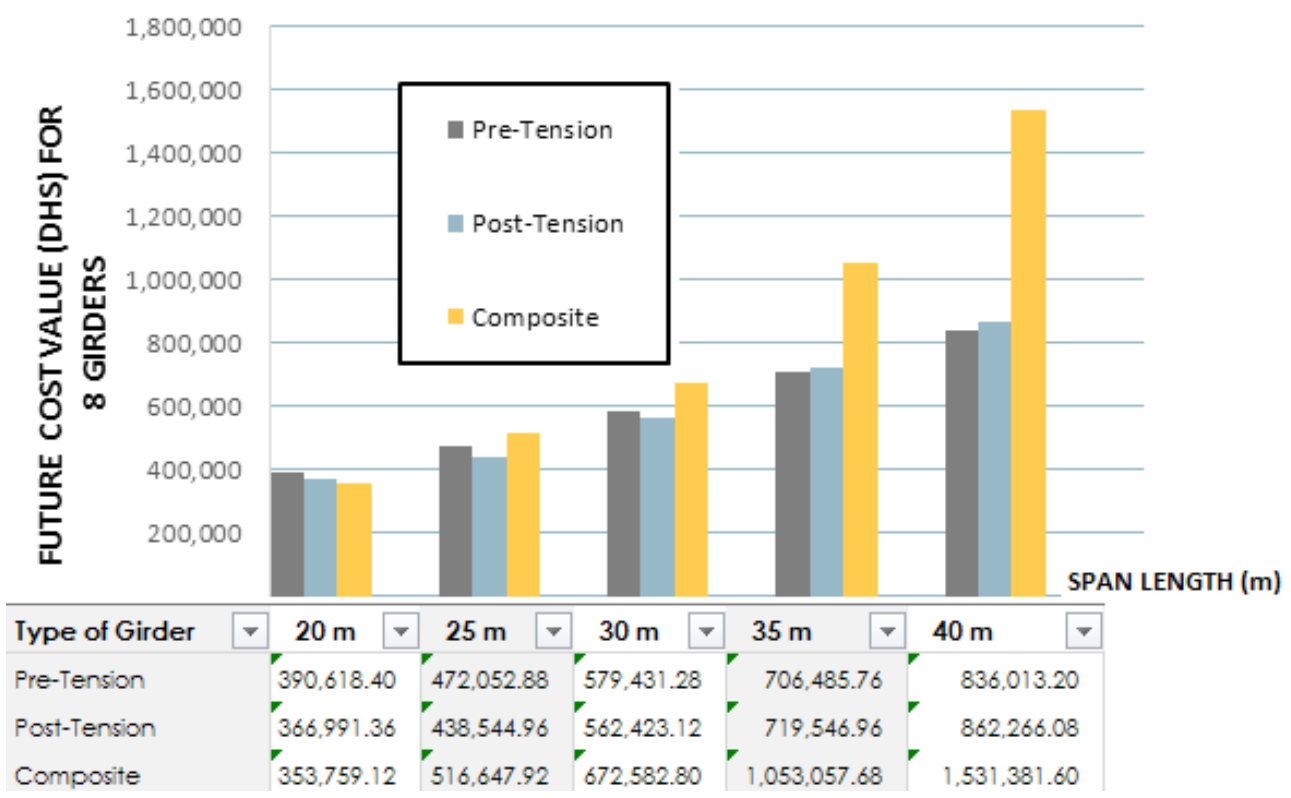

Fig. 5. The total 50 -year total life cycle cost (future value) for 8 -girders of different span and section type.

The conclusion can be seen in Figure 6 which demonstrates the relative differences in cost for both steel composite section and pre-stressed concrete section for all spans. Figure 6 clarifies the considerable impact of maintenance and life cycle costs. Without maintenance consideration, the cost of composite-girder bridge is lower than the prestressed one up to span $30 \mathrm{~m}$. While, the 50 -year life cycle cost with maintenance is always lower for the pre-stressed bridge. It reaches $45 \%$ less than the steel composite 
bridge for 40m span. On the other hand, the FDOT[6] cost can be applicable only for $35 \mathrm{~m}$ bridge span for capital cost and $25 \mathrm{~m}$ bridge span in case of maintenance costs. Otherwise, having pre-stressed bridge provides much lower cost.

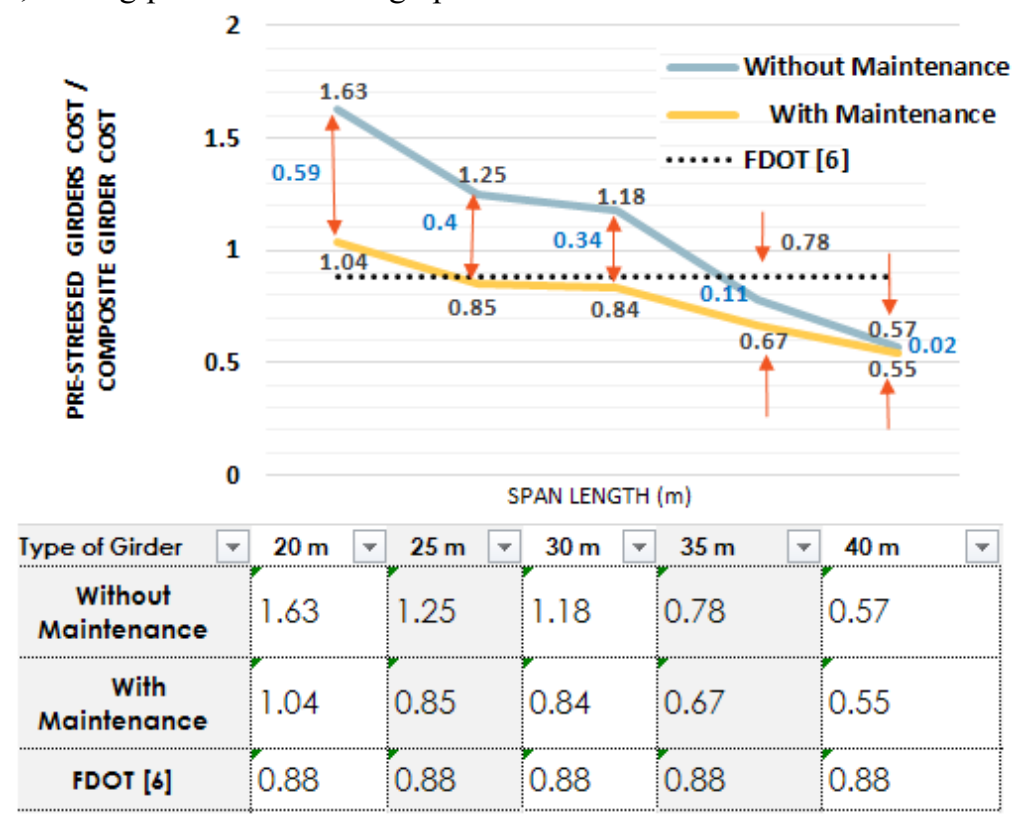

Fig. 6. The relative differences in cost for both steel composite section and pre-stressed section.

\section{Conclusions}

In this paper, three types of girders were investigated: steel composite, pre-tensioned prestressed concrete and post-tensioned pre-stressed concrete. The structural design was analyzed for 5 span lengths: 20,25,30,35 and 40m. Then, the capital construction cost and 50-year life cycle cost were accounted for 15 bridges according to each span and construction materials.

It was found that although steel composite section proposes lower section depth, but the life cycle cost of pre-stressed section is always lower and can reach $45 \%$ of the composite section cost in some cases. It was also evident that the longer the span of the girder the less expensive the pre-stressed section will be.

\section{References}

1. J. Memmott, Highway Bridges in the United States-an Overview, U.S. Department of Transportation, Bureau of transportation statics, special report (2006).

2. Road and Transport Authority (RTA), RTA statistics 2012 (2012).

3. B. Boatman, Prestressed vs. Steel Beams: Expected Service Life, Michigan Department of Transportation, State of Michigan (2010).

4. B. C. Bhagyashree C Jagtap and M. Shahezad, Comparative Study of Prestressed Concrete Girder and Steel Plate Girder for Roadway Over Bridge, International Journal of Scientific Research in Science, Engineering and Technology (IJSRSET), 2(1), pp.113-117 (2016). 
5. N. Singh, N.P. Devgan, A.M. Kalra and S. Surinder Pal, Effect on Economy on Successive Increase in the Span of Bridges, Proceedings of the 2nd International Conference on Civil, Structural and Transportation Engineering (ICCSTE'16), Ottawa, Canada, May 5 - 6, Paper No. 114, pp. 1-8 (2016).

6. Florida Department Of Transportation (FDOT), Bridge Costs, Transportation costs reports, April 29 (2014).

7. Highway Agency, BD37/01: Design manual for road and bridges: Loads for Highway Bridges, London (2002).

8. Computer and structures, Inc., SAP2000: Structural Analysis Program, V15.0.1, Berkeley (2011).

9. British Standards Institution (BSI), BS 5950-3.1: 1990, Structural use of steel work in building, Part 3: Design in composite construction, Section 3.1 Code of practice for design of simple and continuous composite beams, London (2002).

10. British Standards Institution, BS 8110-1: 1997 Structural use of concrete, Part 1: Code of practice for design and construction, London (2002).

11. H.K.Baker and G.E. Powell, Understanding Financial Management, Blackwell Publishing Ltd., USA (2005). 


\section{APPENDIX A: Estimated sections for five different spans girder- bridge}
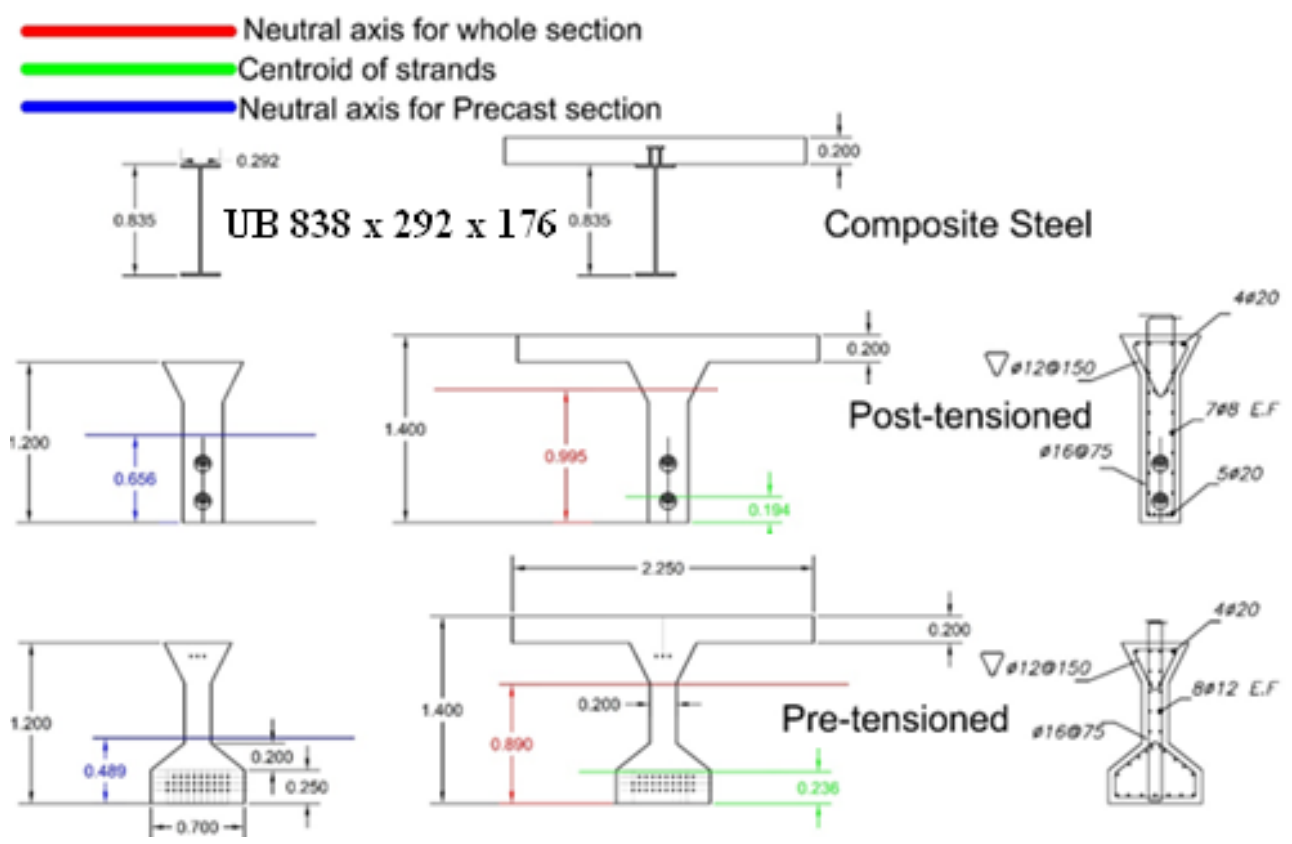

Fig. A-1. Estimated sections for 20m-span bridge.
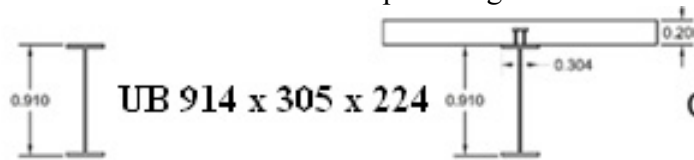

Composite Steel
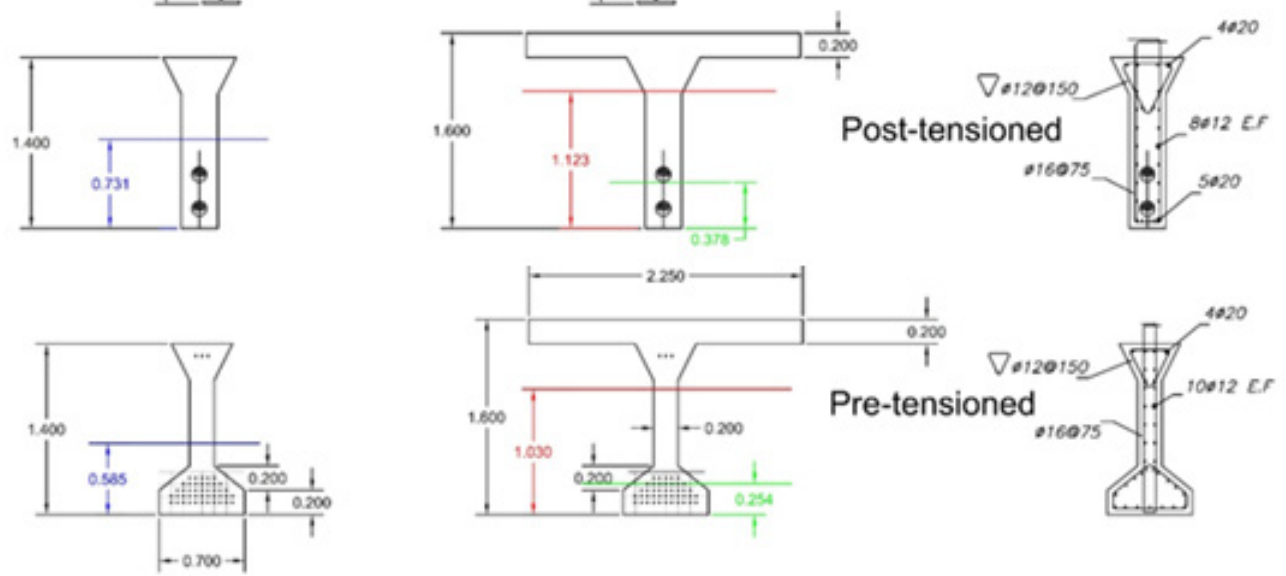

Fig. A-2. Estimated sections for $25 \mathrm{~m}$-span bridge. 

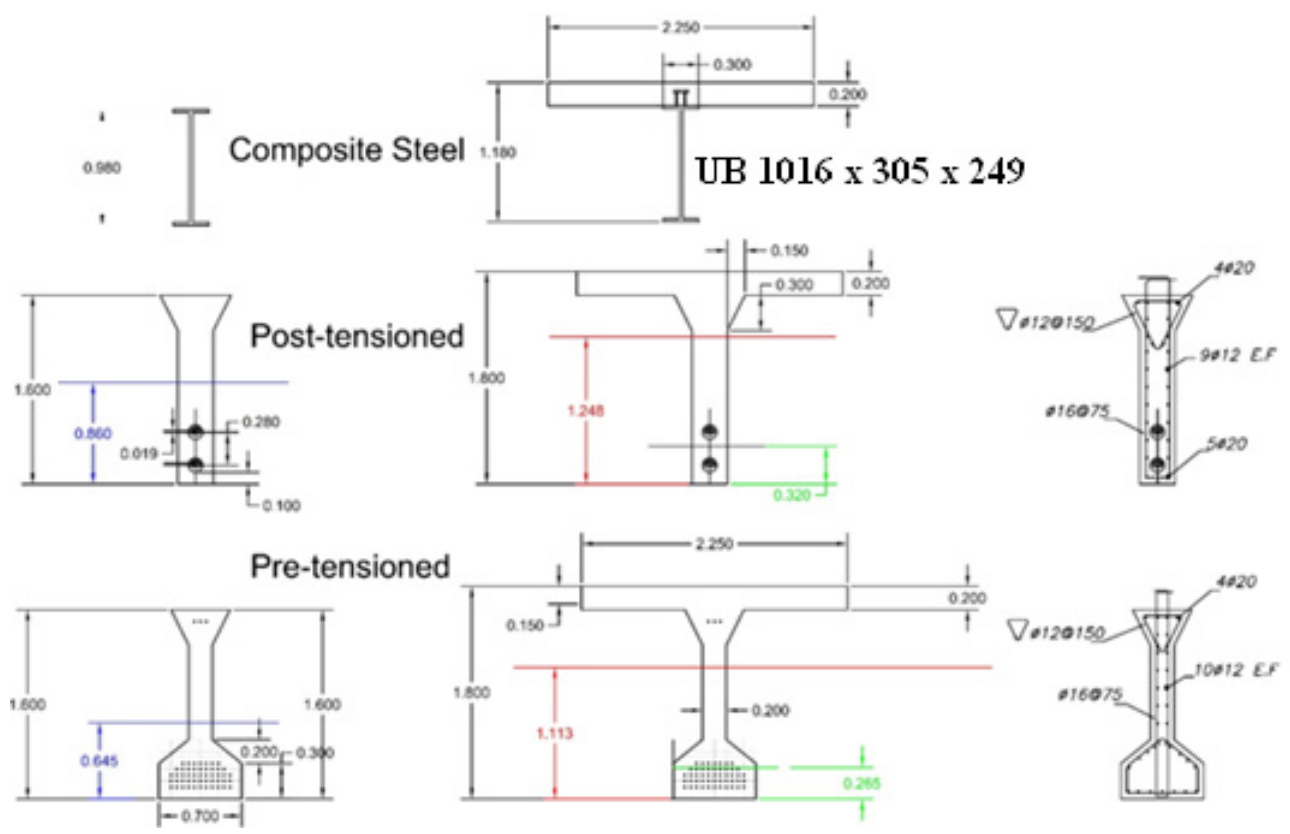

Fig. A-3. Estimated sections for 30m-span bridge.
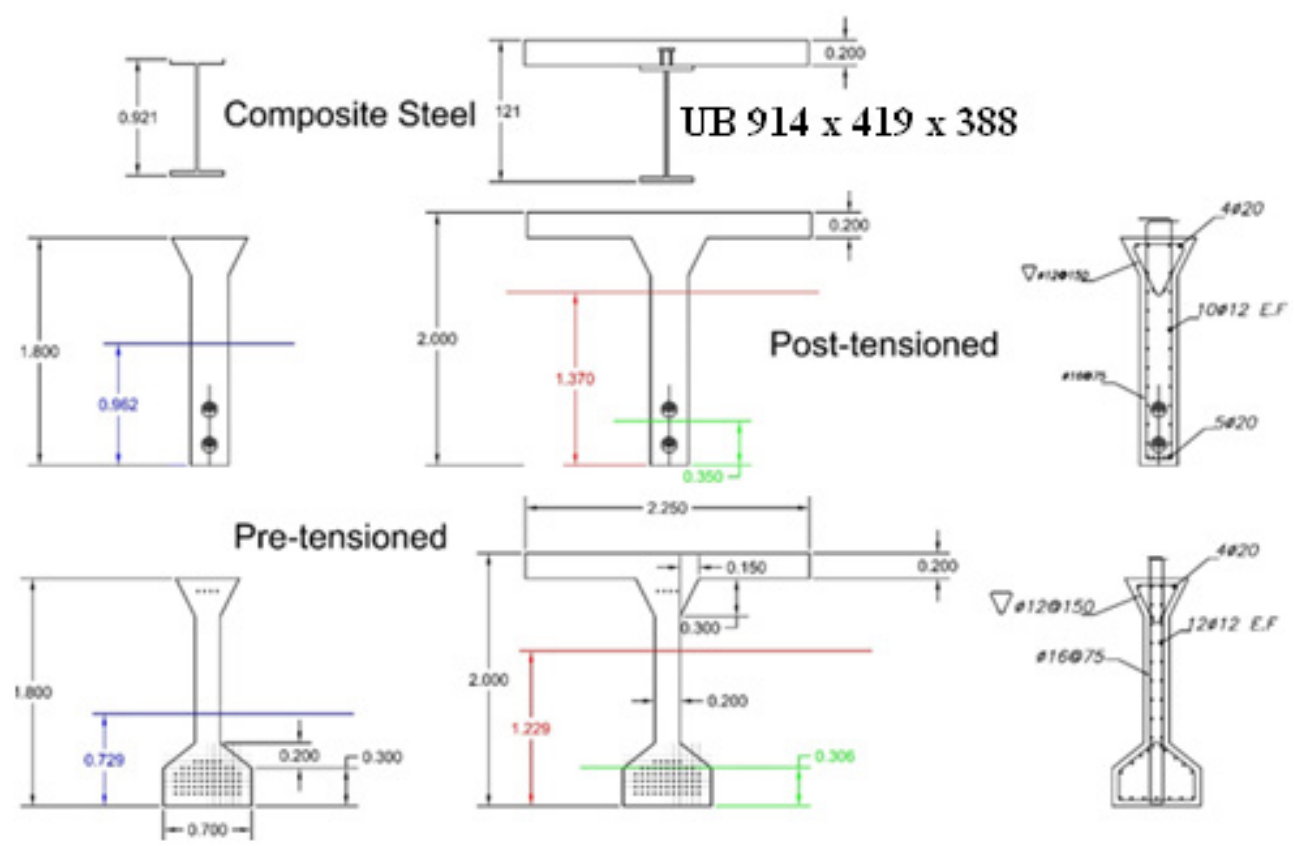

Fig. A-4. Estimated sections for 35m-span bridge. 

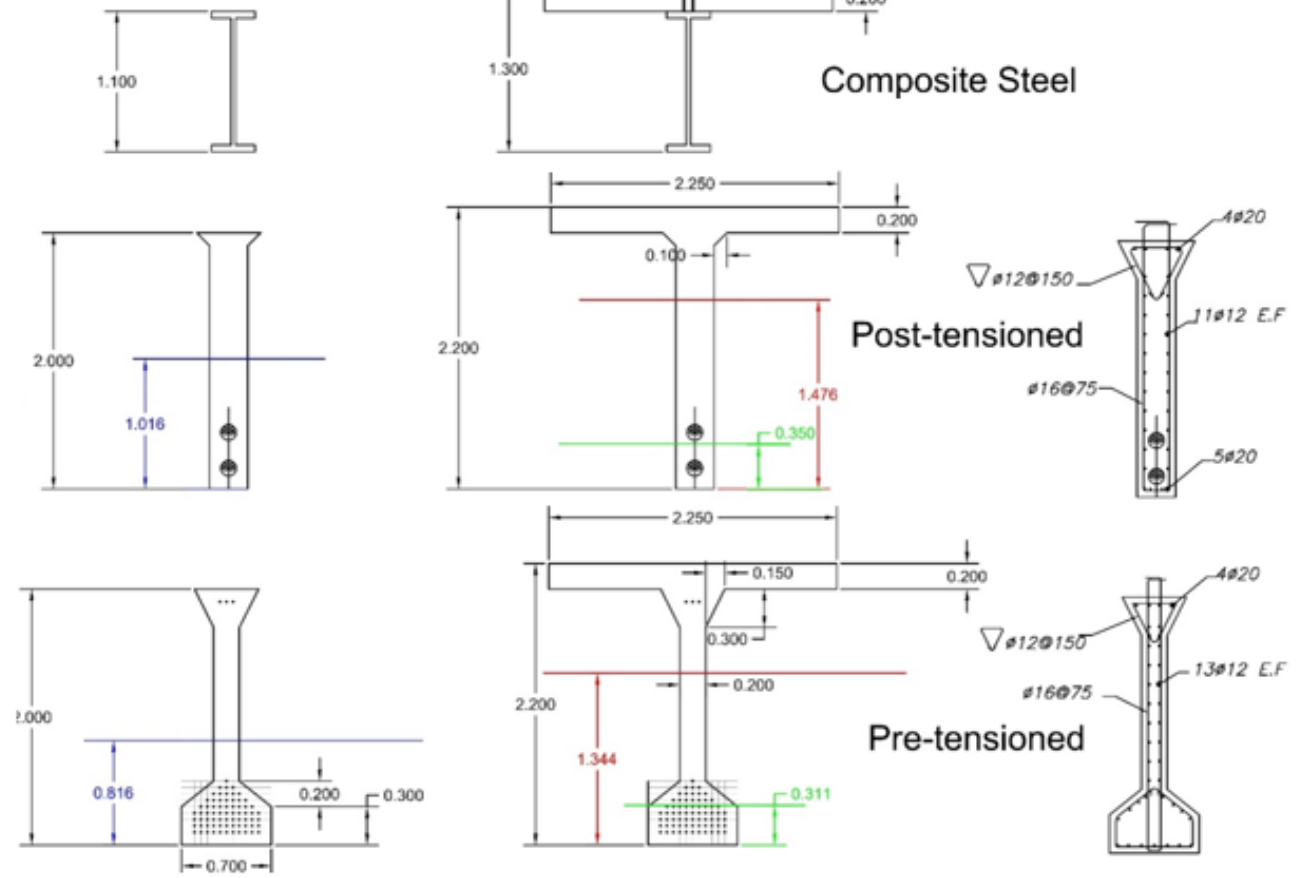

Fig. A-5. Estimated sections for 40m-span bridge. 